\title{
Efeito de Inoculante Bacteriano sobre a Qualidade da Silagem e Perda de Matéria Seca durante a Ensilagem de Sorgo
}

\author{
André de Faria Pedroso1, Alfredo Ribeiro de Freitas ${ }^{2}$, Gilberto Batista de Souza ${ }^{3}$
}

\begin{abstract}
RESUMO - O objetivo deste trabalho foi avaliar o efeito de um inoculante bacteriano comercial, contendo Lactobacillus plantarum, Streptococcusfaecium e Pediococcus acidactili, sobre a qualidade da silagem e perda de matéria seca (MS) durante a ensilagem de sorgo (Sorghum bicolor L. Moench). Os tratamentos foram constituídos por dois tipos de silagem de sorgo duplo-propósito colhido no estádio farináceo: sem (controle) e com inoculante; três posições dentro de cada silo (região do terço inicial, região central e do terço final), correspondendo a três períodos de coleta (52, 65 e 71 dias de fermentação) e três repetições em cada posição. Cada repetição foi constituída por um saco de tela plástica de malha fina, contendo aproximadamente $4 \mathrm{~kg}$ de forragem, sendo a parcela representada por uma amostra de aproximadamente $1 \mathrm{~kg}$ de forragem. A silagem com inoculante apresentou menor teor de cinza (matéria mineral), nitrogênio amoniacal e ácido láctico e níveis mais elevados de fibra em detergente neutro e fibra em detergente ácido. A silagem com inoculante não diferiu do controle em relação ao $\mathrm{pH}$, à proteína bruta, energia bruta e porcentagem de perda da MS.
\end{abstract}

Palavras-chave: inoculante bacteriano, perda matéria seca, qualidade silagem, sorgo

\section{Effect of Bacterial Inoculant on Silage Quality and Dry Matter Loss during Ensiling of Sorghum Silage}

\begin{abstract}
The objective of this work was to evaluate the effect of a commercial bacterial inoculant containing Lactobacillus plantarum, Streptococcus faecium and Pediococcus acidactili on the quality and dry matter (DM) loss of sorghum (Sorghum bicolor L. Moench) during the ensilage process. The treatments were constituted of two types dual propose sorghum silage harvested at the dough stage: without (control) and with inoculant; three positions in each silo (front, middle and back regions) corresponding to three periods of collection (52, 65 and 71 days of fermentation) and three replicates in side each position. Each replicate was constituted of a fine meshed nylon bag with $4 \mathrm{~kg}$ of forage containing $1 \mathrm{~kg}$ of forage approximately. The inoculated silage had lower ash (mineral matter) percentage, ammonia nitrogen and lactic acid, higher content of neutral detergent fiber and acid detergent fiber. The silage with inoculant did not differ from the control in relation to the $\mathrm{pH}$, crude protein, gross energy and percentage of DM loss.
\end{abstract}

Key Words: bacterial inoculant, dry matter loss, quality of silage, sorghum

\section{Introdução}

A fermentação anaeróbica é o principal processo envolvido na preservação das silagens. A eficiência do processo fermentativo e, conseqüentemente, a qualidade da silagem dependem das bactérias epífitas que são colocadas dentro do silo com a forragem. A população de microorganismos epifíticos, entre eles as bactérias produtoras de ácido láctico, pode ser pequena nas forragens (SPECKMAN et al., 1981), sendo afetada pelas condições ambientais (umidade, temperatura, radiação solar, espécie e características da planta), o que pode levar, ao longo do tempo, à obtenção de silagens de qualidade variável, a partir de um mesmo tipo de forragem e sistema de manejo (ASHBELL, 1995). Atualmente, os inoculantes bacterianos para silagem são bastante populares em alguns países e começam a ser comercializados também no Brasil.

Resultados de pesquisa mostram que o aumento artificial da quantidade inicial de bactérias produtoras de ácido láctico na forragem pode favorecer a fermentação e resultar em silagens de melhor qualidade, promovendo queda mais rápida do $\mathrm{pH}$, valor final do pH mais baixo, aumento na relação entre os ácidos láctico e acético e diminuição nos teores de etanol e nitrogênio amoniacal (BOLSEN et al., 1995).

BOLSEN et al. (1995), em sumário de 26 estudos, afirmaram que, em 19 experimentos com silagens de milho e 10 experimentos com silagem de sorgo, a adição de inoculantes bacterianos diminuiu as perdas de matéria seca (MS), melhorando também a qualida-

\footnotetext{
${ }^{1}$ Pesquisador da Embrapa Pecuária Sudeste, Caixa Postal 339, 13560-970 - São Carlos, SP. E.mail: andref@cppse.embrapa.br

2 Pesquisador da Embrapa Pecuária Sudeste, Bolsista do CNPq. E.mail: ribeiro@cppse.embrapa.br

3 Químico da Embrapa Pecuária Sudeste. E.mail: gilberto@cppse.embrapa.br
} 
de das silagens. Outros trabalhos, no entanto, mostraram resultados variáveis quanto ao efeito de inoculantes bacterianos sobre a qualidade e preservação de silagens de milho e sorgo. KUNG et al. (1993) realizaram dois experimentos em que foi avaliado o efeito de dois inoculantes comerciais, contendo Lactobacillus plantarum e Streptococcus faecium, sobre a composição de silagens de milho. Em um experimento preliminar, o uso dos inoculantes causou efeitos negativos e significativos sobre a qualidade das silagens, com elevação do pH e aumento de acido acético e nitrogênio amoniacal. Em um segundo experimento, verificaram que a adição de inoculante não teve efeito sobre a qualidade da silagem tratada.

RODRIGUES et al. (1994) estudaram o efeito de inoculante contendo L. plantarum sobre a silagem de sorgo forrageiro, produzida em micro silos, concluindo que houve efeito positivo, com redução do pH e maior população de bactérias produtoras de acido láctico na silagem proveniente da forragem inoculada.

FROETSCHEL et al. (1994) ensilaram milho e sorgo, com ou sem inoculante, em silos de concreto com capacidade para $900 \mathrm{~kg}$ e detectaram aumento do teor dos ácidos láctico, acético e graxos voláteis totais e diminuição na perda da MS em 7,1\%, concluindo que houve melhor preservação para as forragens inoculadas.

Considerando que os resultados obtidos pela pesquisa têm sido variáveis, quanto à eficácia de inoculantes bacterianos sobre a qualidade e preservação das silagens, e, segundo ASHBELL (1995), inoculantes usados com sucesso em determinada região podem não ser eficientes em outras, indicando influência de condições locais sobre o efeito dos inoculantes, são necessários estudos para avaliação da eficácia dos inoculantes bacterianos comercializados no Brasil, dentro das nossas condições de produção.

O objetivo deste experimento foi avaliar o efeito de inoculante bacteriano comercial sobre a qualidade e perda da MS em silagem de sorgo, nas condições edafoclimáticas do Sudeste do Brasil.

\section{Material e Métodos}

O sorgo, AG 2005 E - duplo propósito da Agroceres, foi cultivado em área de 20 ha de solo Latossolo Vermelho Amarelo (Lva), originalmente distrófico, textura média, na Embrapa/Centro de Pesquisa de Pecuária do Sudeste, município de São Carlos, SP. A semeadura foi realizada em novembro de 1996, com espaçamento de $80 \mathrm{~cm}$ entre linhas, para densidade final de 130.000 plantas/ha. A colheita do sorgo foi realizada com uma ensiladeira regulada para picagem em partículas de $1 \mathrm{~cm}$ de comprimento, quando os grãos da porção mediana das panículas se encontravam no estádio farináceo (105 dias após a semeadura). As silagens foram produzidas em silos de superfície medindo aproximadamente 7,0 m de largura, 1,5 m de altura e $15 \mathrm{~m}$ de comprimento, que apresentaram, quando prontos, seção transversal semicircular. Os silos, com $60 \mathrm{t}$ cada, foram produzidos seqüencialmente, com a finalidade de evitar contaminação da forragem controle com o inoculante e para maior facilidade de operação. Para compactação do material nos silos, foi utilizado trator de pneu de 6,7 t.

O inoculante comercial (Sil-All da Alltech do Brasil, Curitiba, PR) contendo Lactobacillus plantarum, Streptococcus faecium e Pediococcus acidactili foi aplicado diluído em água, de acordo com as instruções do fabricante, para concentração de $10 \mathrm{~g}$ do produto por tonelada de material fresco, utilizando-se pulverizador de pressão variável (AG25 HAY SPRAYER; AG Spray Equipment, Inc. Hopkinsville, KY). A aplicação foi feita, durante a colheita do sorgo, por meio de bico pulverizador localizado na bica da ensiladeira, buscando-se a distribuição uniforme do produto.

Os tratamentos foram constituídos por dois tipos de silagem: sem (controle) e com inoculante; três posições dentro de cada silo (região do terço inicial, região central e região do terço final), correspondendo a três períodos de coleta e três repetições em cada posição. Cada repetição foi constituída por um saco de tela plástica de malha fina, contendo quatro $\mathrm{kg}$ de forragem, colocados dentro dos silos durante a ensilagem, em uma posição afastada em relação às laterais e à altura mediana em relação ao solo e o topo dos silos, de maneira semelhante à utilizada por ASHBELL e LISKER (1988). No momento da ensilagem, foram retirados de cada saco aproximadamente $1 \mathrm{~kg}$ de forragem (parcela experimental), para determinação da MS e análises bromatológica, sendo que as análises de $\mathrm{pH}$ e ácido láctico foram realizadas com amostras do material fresco.

Os silos foram abertos, simultaneamente, após 45 dias de fermentação, para fornecimento da silagem aos animais do rebanho leiteiro da Embrapa Pecuária Sudeste. Os sacos de tela plástica foram removidos durante o descarregamento normal dos silos, aos 52, 65 e 71 dias de fermentação, quando foi possível o acesso aos sacos do terço inicial, do meio e do terço 
50 Rev. bras. zootec.

final, respectivamente. Imediatamente após a remoção, os sacos foram pesados para cálculo da recuperação da MS, sendo retiradas, em seguida, três amostras de silagem, de cada saco, para análise da qualidade das silagens.

Os procedimentos analíticos utilizados para avaliação das silagens foram: a MS foi determinada pela secagem em estufa a $60^{\circ} \mathrm{C}$ por $48 \mathrm{~h}$; o teor de cinza foi obtido pela calcinação em forno mufla a $600^{\circ} \mathrm{C}$ por quatro horas; a fibra em detergente neutro (FDN) e fibra em detergente ácido (FDA) foram determinadas pelo método de Van Soest (ASSOCIATION OF OFFICIAL ANALYTICAL CHEMISTS - AOAC, 1995); o teor de proteína bruta (PB) pela decomposição das proteínas e outros componentes nitrogenados na presença de $\mathrm{H}_{2} \mathrm{SO}_{4}$ concentrado a quente, segundo o método Semi-micro Kjeldahl (AOAC, 1985); a energia bruta (EB) foi determinada pela oxidação completa de amostras em bomba calorimétrica adiabática - tipo Parr (SILVA, 1981); o pH foi obtido colocando-se $9 \mathrm{~g}$ da amostra de silagem fresca em $60 \mathrm{~mL}$ de água destilada durante $30 \mathrm{~min}$ e posterior leitura em potenciômetro com eletrodo combinado de vidro (SILVA, 1981); o ácido láctico foi determinado por espectrofotometria pelo método do cloreto férrico (SILVA, 1981); e o nitrogênio amoniacal $\left(\mathrm{N}-\mathrm{NH}_{3}\right)$, por intermédio da destilação por arraste a vapor (AOAC, 1995).

O modelo matemático utilizado foi:

$$
\begin{aligned}
& y_{i j k}=\mu+T_{i}+P_{j(i)}+\varepsilon_{i j k} \\
& i=1,2 ; j=1,2,3 ; k=1,2,3
\end{aligned}
$$

em que

$\mathrm{y}_{\mathrm{ijk}}=$ valor observado na $\mathrm{k}$-ésima repetição da posiçã̃o j do tratamento i;

$\mu=$ constante, comum a todas as observações;

$\mathrm{T}_{\mathrm{i}} \quad=$ efeito do i-ésimo tratamento;

$P_{j(i)}=$ efeito da j-ésima posição dentro do iésimo tratamento; e

$\varepsilon_{\mathrm{ijk}}=$ erro aleatório suposto da distribuição normal, de média zero e variância $\sigma^{2}$, ou seja, $\varepsilon_{\mathrm{ijk}} \sim$ $\mathrm{N}\left(0, \sigma^{2}\right)$.

\section{Resultados e Discussão}

Na Tabela 1, são apresentados os resultados das análises químicas do material verde e das silagens (controle e tratada com inoculante bacteriano) e parâmetros de fermentação destas. O teor elevado de MS do sorgo (40,6\%), aliado ao uso de silos de superfície, poderia ter acarretado problemas de compactação, pois, normalmente, nestas situações torna-se difícil a obtenção de densidade entre $500 \mathrm{e}$ $600 \mathrm{~kg} / \mathrm{m}^{3}$ na massa ensilada, necessária para retirada do ar, promovendo aquecimento excessivo e aumento das perdas de nutrientes da silagem (NUSSIO, 1991). No entanto, a picagem correta e uniforme do material, em tamanho médio de partículas de $1 \mathrm{~cm}$, e a compactação com trator de grande porte evitaram este problema, permitindo a obtenção de silagens com excelente aspecto visual, cheiro agradável, $\mathrm{pH}$ próximo a 4, teor de nitrogênio amoniacal em relação ao nitrogênio total $\left(\mathrm{N}-\mathrm{NH}_{3} / \mathrm{NT}\right)$ ao redor de $15 \%$ da MS e teor de ácido láctico menor que 5\% na MS (Tabela 1); valores que caracterizam silagens de boa qualidade (Mc CULLOUGH, 1978).

A aplicação do inoculante bacteriano teve efeito variável sobre a qualidade nutricional e parâmetros de fermentação da silagem (Tabela 1). Considerando-se a média dos resultados nos três períodos de coleta dos sacos, alguns aspectos benéficos foram observados com a adição do inoculante, como menor $(\mathrm{P}<0,05)$ teor de cinza $(3,55$ e $3,96 \%$ da MS) e nitrogênio amoniacal $(0,07$ e $0,08 \%$ da MS). O menor teor de cinza é indicativo de melhor conservação da forragem, pois, quando há fermentação inadequada, ocorrem perdas de material orgânico, aumentando a participação relativa da cinza (matéria mineral) na MS (ASHBELL, 1995).

Por outro lado, a silagem tratada com inoculante apresentou menor $(\mathrm{P}<0,05)$ nível de ácido láctico que o controle (4,11 e 4,78\% da MS), o que também foi obtido por KUNG et al. (1993), quando avaliaram o efeito de inoculantes comerciais sobre a composição química de silagens de milho, obtendo efeito negativo pequeno, porém significativo, sobre a qualidade das silagens.

Quanto aos parâmetros nutricionais, a silagem tratada com inoculante mostrou níveis mais elevados $(\mathrm{P}<0,05)$ de FDN $(41,28$ e $39,14 \%$ da MS) e FDA (24,89 e $22,53 \%$ da MS), evidenciando maior perda de material solúvel, porém não diferiu quanto ao teor de PB (7,93 e 7,99\% da MS) e EB (4,46 e 4,44 kcal/ $\mathrm{g}$ da MS), em relação ao controle. Estes resultados confirmam os obtidos por WEINBERG et al. (1993), que, estudando o efeito da aplicação de inoculantes comerciais contendo L. plantarum, E. faecium e P. acidilactici sobre a estabilidade aeróbica de diversos tipos de silagens, não observaram efeito do inoculante sobre os parâmetros nutricionais da silagem de sorgo.

A silagem tratada também não diferiu do controle em relação à porcentagem de perda da MS (2,14 e 
Tabela 1 - Média dos efeitos do inoculante bacteriano sobre a qualidade, os parâmetros de fermentação e a perda de matéria seca da silagem de sorgo (C: controle, I: inoculada)

Table 1 - Mean of the effects of bacterial inoculant on quality, fermentation parameters and dry matter loss of sorghum silage (C: control, I: inoculated)

\begin{tabular}{|c|c|c|c|c|c|c|c|c|c|c|c|}
\hline \multirow[t]{3}{*}{$\begin{array}{l}\text { Parâmetro } \\
\text { Parameter }\end{array}$} & \multirow[t]{3}{*}{$\begin{array}{c}\text { Forragem verde } \\
\text { Fresh forage }\end{array}$} & \multicolumn{6}{|c|}{$\begin{array}{l}\text { Período de coleta }{ }^{1} \\
\text { Time of sampling }\end{array}$} & \multicolumn{2}{|c|}{ Silos } & \multirow{3}{*}{$\mathrm{s}(\overline{\mathrm{X}})$} & \multirow{3}{*}{$\mathrm{CV} \%$} \\
\hline & & \multicolumn{3}{|c|}{$\mathrm{C}$} & \multicolumn{3}{|c|}{ I } & \multirow[t]{2}{*}{$\mathrm{C}$} & \multirow[t]{2}{*}{$\mathrm{I}$} & & \\
\hline & & 52 dias & 65 dias & 71 dias & 52 dias & 65 dias & 71 dias & & & & \\
\hline $\begin{array}{l}\mathrm{MS}(\%) \\
D M\end{array}$ & 41,36 & $40,59^{\mathrm{a}}$ & $42,33^{b}$ & $40,93^{\mathrm{a}}$ & $41,67^{\mathrm{a}}$ & $42,29^{b}$ & $41,20^{\mathrm{a}}$ & $41,28^{\mathrm{a}}$ & $41,72^{\mathrm{b}}$ & 0,12 & 0,80 \\
\hline $\begin{array}{l}\mathrm{FDN}^{2} \\
N D F\end{array}$ & 46,39 & $36,67^{\mathrm{a}}$ & $38,86^{\mathrm{b}}$ & $41,90^{c}$ & $44,48^{\mathrm{a}}$ & $35,36^{\mathrm{b}}$ & $44,02^{\mathrm{a}}$ & $39,14^{\mathrm{a}}$ & $41,28^{b}$ & 0,50 & 3,70 \\
\hline $\begin{array}{l}\text { FDA }^{2} \\
A D F\end{array}$ & 25,19 & 21,91 & 21,99 & 23,70 & $23,88^{\mathrm{a}}$ & $23,68^{\mathrm{a}}$ & $27,12^{b}$ & $22,53^{\mathrm{a}}$ & $24,89^{\mathrm{b}}$ & 0,38 & 4,80 \\
\hline $\begin{array}{l}\mathrm{PB}^{2} \\
C P\end{array}$ & 8,24 & $7,79^{a}$ & $8,24^{\mathrm{ab}}$ & $7,94^{\mathrm{a}}$ & $7,90^{\mathrm{ab}}$ & $7,74^{\mathrm{a}}$ & $8,15^{\mathrm{b}}$ & 7,99 & 7,93 & 0,07 & 2,70 \\
\hline $\begin{array}{l}\mathrm{EB}(\mathrm{kcal} / \mathrm{g} \mathrm{MS}) \\
G E(k c a l / g D M)\end{array}$ & 4,39 & 4,45 & 4,44 & 4,44 & $4,50^{\mathrm{a}}$ & $4,47^{\mathrm{ab}}$ & $4,42^{\mathrm{b}}$ & 4,44 & 4,46 & 0,12 & 0,80 \\
\hline $\begin{array}{l}\text { Cinza }^{2} \\
\text { Ash }\end{array}$ & 3,75 & $3,79^{\mathrm{a}}$ & $4,20^{\mathrm{b}}$ & $3,89^{\mathrm{ab}}$ & $3,76^{\mathrm{a}}$ & $3,27^{\mathrm{b}}$ & $3,61^{\mathrm{a}}$ & $3,96^{\mathrm{a}}$ & $3,55^{\mathrm{b}}$ & 0,06 & 4,90 \\
\hline PH & - & $4,00^{\mathrm{a}}$ & $4,08^{\mathrm{ab}}$ & $4,06^{\mathrm{a}}$ & 4,12 & 4,06 & 4,09 & 4,05 & 4,09 & 0,02 & 1,10 \\
\hline $\begin{array}{l}\text { Ac. } \text { Lact }^{2} . \\
\text { Lac. Ac. }\end{array}$ & - & $3,95^{\mathrm{a}}$ & $5,25^{\mathrm{b}}$ & $5,14^{b}$ & 3,90 & 3,99 & 4,45 & $4,78^{\mathrm{a}}$ & $4,11^{\mathrm{b}}$ & 0,14 & 9,70 \\
\hline $\mathrm{N}-\mathrm{NH}_{3}^{2}$ & - & $0,07 \mathrm{a}$ & $0,09^{\mathrm{b}}$ & $0,08^{b}$ & 0,08 & 0,07 & 0,07 & $0,08^{\mathrm{a}}$ & $0,07^{b}$ & 0,00 & 8,80 \\
\hline $\mathrm{N}-\mathrm{NH}_{3} / \mathrm{NT}(\%)$ & - & 14,79 & 16,87 & 14,28 & $16,79^{\mathrm{a}}$ & $13,17^{\mathrm{b}}$ & $13,55^{\mathrm{b}}$ & 15,31 & 14,50 & 0,57 & 11,4 \\
\hline $\begin{array}{l}\text { Perda MS (\%) } \\
\text { DM loss }\end{array}$ & - & $2,16 \mathrm{a}$ & $1,90^{\mathrm{a}}$ & $5,12^{\mathrm{b}}$ & $2,42^{\mathrm{ab}}$ & $0,31^{\mathrm{a}}$ & $3,70^{\mathrm{b}}$ & 3,06 & 2,14 & 0,40 & 45,5 \\
\hline
\end{tabular}

Médias, na linha, seguidas de diferentes letras são diferentes $(P<0,05)$ dentro de período de coleta $(C$ ou I) e de silo $(C$ vs $I)$.

Means, within a row followed by different letters are different $(P<0.05)$ within time of sampling $(C$ or $I)$ and silo $(C$ vs $I)$.

1 Períodos de coleta correspondem ao tempo de fermentação e às posições dentro dos silos (52 dias-frente; 65 dias-meio; 71 dias-fundo).

1 Time of sampling correspond to the period of fermentation and the position inside the silo (52 days-front; 65 days-middle, 71 days-end).

2 (\% MS) (\% DM).

3,06\% da MS) e pH $(4,09$ e 4,05). Estes níveis de perdas são considerados pequenos e, juntamente com o pH baixo, evidenciam que os processos de produção e fermentação das silagens foram adequados.

Considerando que: silagens de sorgo são materiais relativamente grosseiros (mistura de fragmentos de colmos, folhas e sementes), podendo levar a pequenas variações na composição das amostras e nos resultados das análises; as diferenças entre os tratamentos foram pequenas (apesar de estatisticamente diferentes em alguns casos); e, entre os períodos de coleta, houve variações nos resultados dentro do mesmo parâmetro analisado (como no caso da FDN, $\mathrm{PB}, \mathrm{EB}$, do $\mathrm{pH}, \mathrm{N}_{-} \mathrm{NH}_{3}$ e da perda de MS), pode-se inferir que não houve efeito consistente do inoculante neste experimento em relação à qualidade da silageme perda de MS durante a ensilagem.

O fato de a silagem controle também ter sido de boa qualidade (considerando-se a análise bromatológica, parâmetros de fermentação, aspecto visual, aroma, consumo pelos animais e perda de MS) indica que a mesma possuía inicialmente os requisitos, como teor de MS, açúcares solúveis, compactação e população de bactérias produtoras de ácido láctico, para fermentação adequada, tornando desnecessário o uso do inoculante.

\section{Conclusões}

A aplicação do inoculante bacteriano não teve efeito consistente sobre a qualidade e parâmetros de fermentação da silagem, não alterando também a perda de matéria seca durante a ensilagem do sorgo.

\section{Referências Bibliográficas}

ASHBELL, G. 1995. Basic principles of preservation offorage, by-products and residues as silage or hay. Bet Dagan: Agricultural Research Organization, The Volcani Center. (n.1664-E). 58p.

ASHBELL, G., LISKER, N. 1988. Aerobic deterioration in maize silage stored in a bunker silo under farm conditions in a subtropical climate. J. Sci. Food Agric., 45(4):307-315.

ASSOCIATION OF OFFICIAL ANALYTICAL CHEMISTS AOAC. 1995. Official Methods of Analysis. 16.ed. AOAC, Washington, DC.

BOLSEN, K.K., ASHBELL, G., WILKINSON, J.M. 1995. Silage additives. In: WALLACE, J., CHESSON, A. (Ed.) Biotechnology in animal feeds and animalfeeding. New York: VCH Weinheim. p.33-54.

FROETSCHEL, M.A., NICHOLS, S. W., AMOSS, H.E. et al. 1994. Effects of inoculation on preservation and utilization of tropical corn and sorghum silages. J. Anim. Sci., 72(supl.1), J. Dairy Sci., 77:338. (Suppl.1).

KUNG, L., CHEN, J.H., KRECK, E.M. et. al. 1993. Effect of 
52 Rev. bras. zootec.

microbial inoculants on the nutritive value of corn silage for lactating dairy cows. J. Dairy Sci., 76(12):3763-3700.

Mc CULLOUGH, M.E. 1978. Silage - Some general considerations. McCULLOUGH, M.E. (Ed.) Fermantation of silage - a review. Des Moines, Iowa: National Feed Ingredients Association, p.3-26.

NUSSIO, L.G. Cultura de milho para produção de silagem de alto valor alimentício. In: SIMPÓSIO SOBRE NUTRIÇÃO DE BOVINOS, 4, 1991, Piracicaba. Anais...Piracicaba: FEALQ, 1991. p.59-168.

RODRIGUES, A.A., RUST, S.R., YOKOYAMA, M.T. et al.1994. Microbial inoculant and enzymes in forage sorghum ensiled under temperate and tropical environments. I. Microbial succession. J. Dairy Sci., 77:301. (Suppl. 1)

SILVA, D.J. 1981. Análise de alimentos (Métodos químicos e biológicos). Viçosa, MG: UFV. 165p.

SPECKMAN, C.A., PHILIPS, R.M., LINNERTZ, D.P. et al.1988. A survey for indigenous Lactobacillus species on standing field corn at ensiling maturity. J. Anim. Sci., 53:99. (Suppl. 1)

STOKES, M.R. 1992. Effect of an enzyme mixture, an inoculant, and their interaction on silage fermentation and dairy production. J. Dairy Sci., 75(3):764-773.
SUAZO, R., SONON, R.N., BOLSEN, K.K. 1993. Effect of hybrid, growing condition, storage time, and Pioneer 1174 silage inoculant on agronomic performance and nutritive value of whole-plant corn and grain sorghum silages. Cattlemen's Day - Report of Progress-678, Agricultural Experiment Station, Kansas State University, Manhattan, Kansas. 8p.

WEINBERG, Z.G., ASHBELL, G., HEN, Y. et al. 1993. The effect of applying lactic acid bacteria at ensiling on aerobic stability of silages. J. Applied Bacteriology, 75(6):512-518.

Recebido em: 29/12/98

Aceito em: 10/08/99 